\title{
Comparison of Pressure-Controlled Ventilation with Volume Guarantee and Volume-Controlled Ventilation mode in Patients under Laparoscopic Surgery: A Meta-Analysis of Randomized Controlled Trials
}

\section{Xiaoxiao Li}

Xuzhou Medical University

Xueli Lv

Xuzhou Medical University

Zhenfei Jiang

Xuzhou Medical University

Xinrui Nie

Xuzhou Medical University

Su Liu ( $\nabla$ liusu112277@gmail.com )

Xuzhou Medical College Affiliated Hospital https://orcid.org/0000-0002-8347-5399

Research article

Keywords: PCV-VG; VCV; Ppeak; Respiratory Mechanics; Meta-Analysis

Posted Date: April 25th, 2019

DOI: https://doi.org/10.21203/rs.2.9365/v1

License: (c) (1) This work is licensed under a Creative Commons Attribution 4.0 International License.

Read Full License 


\section{Abstract}

Background $\mathbb{\text { In }}$ traditional Volume-Controlled Ventilation (VCV) mode, the creation of pneumoperitoneum during laparoscopic surgery may lead to Ventilator-Associated Lung Injury (VALI). Pressure-Controlled Ventilation with Volume Guarantee (PCV-VG) mode ensures providing adequate oxygen supply to patients while reducing the risk of lung injury. Methods $₫$ Eligible randomized clinical trials (RCTs) were searched in Medline, Embase, the Cochrane Central Register of Controlled Trials (CENTRAL), Sino Med, China National Knowledge Infrastructure (CNKI) and Wan-Fang MED without language restriction up to March 2019. The primary outcome of this meta-analysis was airway peak pressure (Ppeak) at 30,60 or 90 mins after complete $\mathrm{CO} 2$ insufflation. This meta-analysis was followed the recommendations of the PRISMA statement. Results $\bowtie$ Finally, 9 articles were included. The Ppeak in the PCV-VG group was lower than that in the VCV group, and the difference was statistically significant at 30mins [Mean Difference $(M D)=-3.55,95 \%$ Confidence Interval $(C l)=-5.13$ to $-1.98, I 2=83 \%], 60 \mathrm{mins}[\mathrm{MD}=-5.76,95 \% \mathrm{Cl}=-8.15-3.36$, I2=93\%], 90 mins [MD $=-4.59,95 \% \mathrm{Cl}=-5.43-3.74, \mathrm{I} 2=30 \%]$ after complete $\mathrm{CO} 2$ insufflation. Meanwhile, PCV-VG mode could effectively reduce airway mean pressure (Pmean) and improve dynamic compliance (Cdyn) of patients after complete $\mathrm{CO} 2$ insufflation in laparoscopic surgery compared to VCV mode. However, no significant difference was found in PetCO2, HR, MAP, PH, PaO2, and PaCO2 between the twoventilation modes. Conclusions: PCV-VG mode are superior to VCV mode in providing adequate oxygenation at lower airway peak pressure and greater dynamic compliance in patients under laparoscopic surgery.

\section{Background}

In the past two decades, the Enhanced Recovery After Surgery (ERAS) concept and laparoscopic technology have promoted the enormous progress of surgical operations. Due to the rapid development of the technique of laparoscopy, laparoscopic surgery has attracted more attention [1] and gradually become the preferred treatment for some surgical operations with the advantages of small trauma, less postoperative pain and faster recovery, which can significantly shorten the hospital stay of inpatients [2]. Studies have shown that laparoscopic cholecystectomy can effectively reduce cardiovascular complications six-fold compared with traditional open surgery [3].

However, during laparoscopic surgery, pneumoperitoneum pressure of about $11-15 \mathrm{mmHg}$ would be created to facilitate surgical access. Due to the creation of pneumoperitoneum, a series of pathophysiological changes in cardiorespiratory systems would be generated in patients during the operation, such as the decline in lung compliance [4], increase in airway pressure [5], and reduction in functional residual capacity (FRC). In the severe cases, it could lead to the imbalance of ventilation/perfusion ratio, decreased arterial oxygen levels, lung collapse etc., and promote the occurrence of postoperative pulmonary complications (PPC) [6]. Multiple studies have shown that the application of lung ventilation protection strategy and positive end-expiratory pressure in laparoscopic surgery can reduce the pathophysiological changes caused by pneumoperitoneum $[7,8]$. However, it 
should not be neglected that improper setting of the ventilator is likely to cause VALI. Therefore, reasonable ventilation mode to reduce VALI is particularly important during laparoscopic surgery.

VCV mode is a commonly used conventional mode in laparoscopic surgery, which follows a constant flow pattern to deliver a preset tidal volume during the preset inspiratory time for ensuring constant minute ventilation $[9,10]$. However, this flow pattern generates high airway peak pressure, which can lead to barotrauma and volutrauma to the alveoli [11]; VCV mode would also lead to micro atelectasis as some alveoli with low lung compliance may turn to exhalation status before opening [12].

PCV-VG mode is a new type of intelligent ventilation mode, combined with the advantages of volume control and pressure control ventilation modes [13], delivering tidal volume at a preset pressure and inspiratory time. After setting the target tidal volume, the ventilator would automatically adjust the flow rates based on continuous monitoring of airway pressure and lung compliance [14], aimed at attaining the tidal volume at lower peak inspiratory pressures. Several studies have shown that $[9,12,15,16]$, compared with VCV ventilation mode, PCV-VG ventilation mode has a smaller impact on respiratory mechanics.

Although some RCTs have indicated that PCV-VG pattern could reduce the impact on the respiratory mechanics of patients undergoing laparoscopic surgery and even have certain lung protection effects. However, due to the small sample size and single-center of current clinical study, no comprehensive conclusions so far have been formed to guide clinical practice. According to some studies, we hypothesized that PCV-VG pattern would reduce airway pressure and increase lung compliance compared with VCV mode, which is more suitable for patients undergoing laparoscopic surgery. Therefore, we conducted this meta-analysis to explore the effect of the PCV-VG mode on patients undergoing laparoscopic surgery compared with the VCV mode.

\section{Methods}

\section{Literature search}

To obtain relevant original studies, we searched the following databases: Medline, Embase, CENTRAL, Sino Med, CNKI and Wan-Fang MED without language restriction up to March 2019. We also searched The Clinical Trials Registry (www.clinicaltrials.com), references of included studies and Google Scholar to identify more trials. The process was carried out by two researchers. The literature retrieval was based on the following three aspects: Participants: participants who underwent laparoscopic surgery; Intervention group: PCV-VG mode; Control group: VCV mode. The complete PubMed retrieval strategy is shown in Appendix 1.

\section{Selection criteria}

The study selection process was independently performed by two reviewers. By removing duplicate articles, reading the title and abstract for initial literature screening, and careful reading the full text, the 
remaining studies were included in our meta-analysis. Some disagreements arising during this period were resolved by consultation with a third reviewer. Studies that met all the following criteria were included in this meta-analysis: (1) RCTs; (2) Patients underwent elective laparoscopic surgery, including transperitoneal, retroperitoneal laparoscopic surgery; (3) Ages $\geq 18$ years old; (4) Intervention measures: PCV-VG mode; (4) the ventilation pattern of Control group: VCV mode. (5) Studies contain at least one of the following measured time points: $30 \mathrm{~min}, 60 \mathrm{~min}$ or $90 \mathrm{~min}$ after complete $\mathrm{CO} 2$ insufflation; (6) Studies contain at least one of the following measured outcomes: Ppeak, Pmean, Cdyn, PetCO2, HR, MAP, PH, Pa02, PaC02. Exclusion criteria:(1) Literature review, systematic review, case report, cohort study, etc.; (2) Patients were not intubated; (3) Patients underwent one-lung ventilation; (4) Studies with no target data; (5) Operation duration was less than $1 \mathrm{~h}$; (6) $\mathrm{BMI} \geq 35 \mathrm{~kg} / \mathrm{m} 2$.

Data collection

Before the start of data collection, one author designed the data extraction form that included article title, author, publication year, country, language, group, number of patients in each group, ventilation mode, ventilation setting, surgery type, laparoscopic type, outcome. For the required data unavailable, we would contact with the author for relevant information. The process was carried out independently by two researchers. The controversial sections were discussed by two researchers with a third researcher to reach a consensus. The primary outcome of this meta-analysis was Ppeak at 30,60 or 90mins after complete $\mathrm{CO} 2$ insufflation; The secondary outcomes were Pmean, Cdyn, HR, MAP, PH, PaO2, PaCO2 at the above measure time points.

Risk of bias assessment

11 original articles were selected according to the search strategy. The Review Manager 5.3 software was applied and the quality of the included RCTs was assessed with reference to the Cochrane Reviewer Handbook. Evaluation indicators include: (1) Whether the random sequence is generated correctly; (2)

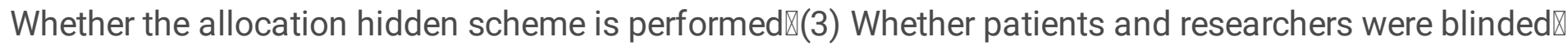

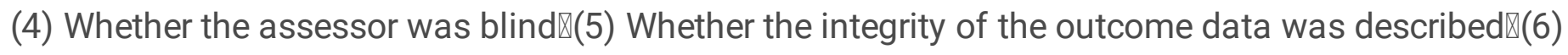
Whether there is selective reporting $₫(7)$ Other biases. Through the above seven aspects, the quality of included studies was assessed and summarized as low, medium or high risk.

Statistical methods

In this study, we used Review Manager 5.3 for the corresponding statistical analysis. For binary outcomes, the Relative Risk (RR) with $95 \% \mathrm{Cl}$ was computed by an inverse variance method. In continuous outcomes, the Mean Difference (MD) with $95 \% \mathrm{Cl}$ was computed using the method of MantelHaenzsel. Heterogeneity was calculated by $X 2$ and $/ 2$ tests [17]. $X 2<0.10$ or a quantitative assessment of the 12 test $>50 \%$ with a $\mathrm{P}$ value $<0.01$ were regarded as obviously heterogeneous, and the results required cautious interpretation. If the heterogeneity is more obvious, we would conduct a sensitivity analysis and analyze the remaining studies by excluding one study at a time to determine whether the results are robust. We conducted subgroup analysis according to the type of laparoscopy, namely whether it is 
retroperitoneal laparoscopy because it has been reported in studies [19-21] that retroperitoneal laparoscopic surgery has a greater impact on respiratory mechanics. Funnel plot analysis was performed to determine whether publication bias existed.

\section{Results}

Study selection

In this meta-analysis, we conducted study selection according to the PRISMA statement and a total of 31 articles were retrieved (Fig.1). After removing duplicate and irrelevant studies, 2 studies were excluded and 9 studies were included in final quantitative analysis.

Study characteristics

Table.1 shows the basic information of the included studies.

Risk of bias

The bias results are shown in Fig.2. The quality of the included studies was evaluated by the Review Manager 5.3 software. The risk of bias in the included RCTs was mainly caused by the absence of random allocation of concealment schemes in multiple studies. Due to the obvious ventilator ventilation mode, the blind method could not be set and the risk of bias could be implemented.

The Primary Outcome: Ppeak

The Ppeak (Fig.3) was reported in 5 articles [16,24,27-29] at 30mins after complete CO2 insufflation. In comparison, the Ppeak in the PCV-VG group was lower than that in the VCV group, and the difference was statistically significant (MD $=-3.55,95 \% \mathrm{Cl}=-5.13$ to $-1.98,12=83 \%) .6$ studies $[9,16,24,28-30]$ reported Ppeak at 60 mins after the pneumoperitoneum has formed. The forest plot showed that patients using PCV-VG mode had lower airway pressure than these in the VCV group $(M D=-5.76,95 \% \mathrm{Cl}=-8.15-3.36$, 12=93\%). 3 studies [27-29] reported the Ppeak at 90 mins after complete CO2 insufflation (MD $=-4.59$, $95 \% \mathrm{Cl}=-5.43-3.74,12=30 \%$, which was still relatively small in patients with PCV-VG mode. Meanwhile, we conducted a subgroup analysis according to whether patients underwent transperitoneal or retroperitoneal laparoscopic surgery (Fig. 4). At 30 and 60 mins after the pneumoperitoneum has formed, the Ppeak in the PCV-VG group was lower than that in the VCV group in whichever type of laparoscopic surgery, and the difference was statistically significant.

The Secondary Outcomes

\section{Pmean}

The Pmean (Fig.5) was reported in 4 RCTs $[16,24,27,28]$ at 30 mins after complete CO2 insufflation, and results showed compared with the VCV group, the Pmean in the PCV-VG group had a lower mean airway pressure $(\mathrm{MD}=-1.83,95 \% \mathrm{Cl}=-2.61$ to $-1.05,12=77 \%) ; 4$ studies $[9,16,24,28]$ reported the Pmean at 60 mins 
after complete $\mathrm{CO} 2$ insufflation. The forest plot showed that the mean airway pressure under PCV-VG mode was lower than that under VCV mode ( $M D=-1.74,95 \% \mathrm{Cl}=-2.99$ to $-0.49,12=94 \%) .2$ studies $[27,28]$ reported the Pmean at 90 mins after complete $\mathrm{CO} 2$ insufflation, which was still lower in the PCV-VG group $(\mathrm{MD}=-1.56,95 \% \mathrm{Cl}=-2.28$ to $-0.84,12=50 \%)$.

Cdyn

3 articles [27-29] reported Cdyn (Fig.6) at 30mins after complete $\mathrm{CO} 2$ insufflation. In comparison, Cdyn in PCV-VG mode was greater than that in VCV mode (MD= 4.59, 95\% $\mathrm{Cl}=3.91$ to $5.28,12=95 \%) .4$ studies [9,28-30] reported Cdyn at 60mins after complete $\mathrm{CO} 2$ insufflation. The forest plot showed that Cdyn in patients under $P C V-V G$ mode was better ( $M D=7.49,95 \% \mathrm{Cl}=4.49$ to $10.49,12=95 \%)$.

\section{PetCO2}

No significant difference was found in PetCO2 (Fig.7) between the two groups among the studies, including at $30 \mathrm{mins}(\mathrm{MD}=-2.70,95 \% \mathrm{Cl}=-5.85$ to $0.45,12=92 \%), 60 \mathrm{mins}(\mathrm{MD}=-0.12,95 \% \mathrm{Cl}=-2.32$ to $0.29,12=61 \%$ ), and 90 mins after complete $\mathrm{CO} 2$ insufflation ( $\mathrm{MD}=0.06,95 \% \mathrm{Cl}=-1.62$ to $1.74,12=47 \%$ ).

\section{Hemodynamic Index}

No significant difference was found in HR (Fig.8) between the two groups reported at 60 mins (MD $=-1.81$, $95 \% \mathrm{Cl}=-7.73$ to $4.11,12=61 \%$ ) after complete $\mathrm{CO} 2$ insufflation. Meanwhile, no significant difference was found in MAP compared PCV-VG group with VCV group at 60 mins after complete $\mathrm{CO} 2$ insufflation (MD= $-2.70,95 \% \mathrm{Cl}=-5.85$ to $0.45,12=92 \%)$.

\section{Arterial Blood Gas Analysis}

The results (Fig.9) showed no difference in $\mathrm{PH}$ between the two modes, including at $30 \mathrm{mins}(\mathrm{MD}=0.01$, $95 \% \mathrm{Cl}=-0.01$ to $0.03, \mathrm{I}=0 \%$ ), and $60 \mathrm{mins}$ after complete $\mathrm{CO} 2$ insufflation (MD $=0.01,95 \% \mathrm{Cl}=-0.00$ to $0.03,12=59 \%)$. No significant difference in $\mathrm{PaO} 2$ was found when compared PCV-VG group with VCV group at 60 mins after complete $\mathrm{CO} 2$ insufflation (MD=1.54, $95 \% \mathrm{Cl}=-8.20$ to $11.29,12=32 \%$ ). In the eligible studies, the difference in $\mathrm{PaCO} 2$ was also insignificant, including at $30 \mathrm{mins}(\mathrm{MD}=-1.49,95 \% \mathrm{Cl}=$ -3.90 to $0.92, \mathrm{I} 2=93 \%), 60$ mins $(\mathrm{MD}=-1.81,95 \% \mathrm{Cl}=-4.86$ to $1.24, \mathrm{I} 2=93 \%)$ after complete $\mathrm{CO} 2$ insufflation.

\section{Publication bias}

We analyzed the included RCTs based on the Ppeak before the initiation of pneumoperitoneum to determine whether there was a publication bias. The bias map showed that the asymmetry between the two was due to a small sample size.

Sensitivity analysis 
We also did a sensitivity analysis and the synthesized outcome remained unchanged after excluding one study each time. The sensitivity analysis results also demonstrated that the outcome result was robust.

\section{Discussion}

In the general anesthesia with mechanical ventilation, a better ventilation mode should provide patients with enough oxygen while minimizing the risk of lung injury, without causing the drastic changes in hemodynamics [12,31]. Our meta-analysis showed that under the condition of pneumoperitoneum, the principal observation was that the Ppeak was significantly lower in the PCV-VG modes compared to the VCV mode; Meanwhile, PCV-VG mode could effectively reduce Pmean and improve Cdyn of patients after the formation of pneumoperitoneum in laparoscopic surgery compared with VCV mode. However, no significant difference was found between the PetCO2, $\mathrm{HR}, \mathrm{MAP}, \mathrm{PH}, \mathrm{PaO} 2$, and $\mathrm{PaCO} 2$ compared with the VCV mode.

Since the conception of ERAS has been put forward in 1990, the effectiveness of a series of interventions in favor of ERAS across the perioperative period has been recognized in clinical practice. Recently, the indepth development of minimally invasive surgical technology has further contributed to the implementation and promotion of ERAS. Laparoscopic surgery has become the preferred surgical method in some abdominal surgeries and urological surgeries because of its small trauma, light postoperative pain, enhanced postoperative recovery, which significantly short inpatients' hospital stay and lowered the incidence of postoperative complication and mortality. However, laparoscopic surgeries require a pneumoperitoneum pressure of around $11-15 \mathrm{mmHg}$, which can cause a series of pathophysiological changes in the respiratory and circulatory systems. For example, the compliance of the lungs and chest wall decreased by about $25 \%$, and the functional residual capacity decreased, eventually leading to imbalance of lung ventilation/perfusion flow, arterial oxygenation, lung collapse, etc., which may lead to postoperative pulmonary complications [4-6].

While ensuring normal ventilation during general anesthesia, mechanical ventilation is also an invasive and non-physiological procedure. The ventilator can perform mechanical ventilation for patients under general anesthesia, maintain the oxygen supply to the patient's tissues during anesthesia, and control the patient's breathing movement by adjusting various parameters. However, the improper setting is likely to cause ventilator-related lung injury, including volume injury, barometric injury, atelectasis injury, and biological injury. Therefore, to reduce ventilator-related lung injury, reasonable adjustments of parameters will be particularly important in mechanical ventilation. PCV-VG mode is a new type of intelligent ventilation mode, combined with the advantages of both volume control and pressure control modes, adjusting automatically according to respiratory dynamic parameters. Decelerating flow is adopted to reduce airway pressure while ensuring the preset tidal volume. By continuously monitoring airway pressure and lung compliance, airway pressure can be automatically adjusted to increase lung compliance [12,32]. 
Ppeak is the maximum pressure during the ventilator's active inflation to the lungs. It needs to overcome the thoracic elastic resistance, lung elastic resistance and airway resistance. The normal range should not exceed 30-35cmH2O. Maeda [33] found that the higher the peak pressure of the airway, the greater the risk of lung injury. Eisner et al. [34] found that Ppeak height is a major risk factor for early barotrauma in patients with lung injury. In our study, we found that the PCV-VG mode significantly reduced the Ppeak after pneumoperitoneum formation compared to the VCV mode. Boules [35] studied the effects of both PCV-VG and VCV ventilation modes on respiratory mechanics and hemodynamic parameters in singlelung ventilation (OLV), which results were like our study that the Ppeak of PCV-VG was significantly lower than that of VCV after pneumoperitoneum formation $(P<0.05)$. Dion [36] observed 20 morbidly obese patients who underwent laparoscopic surgery with VCV, PCV, or PCV-VG mechanical ventilation and found that compared with VCV, the Ppeak values in PCV and PCV-VG modes were lower, which was the same as our research results. At the meantime, we obtained similar results in the subgroup analysis of airway peak pressure according to whether it's laparoscopic or retroperitoneal laparoscopic surgery, and found that 60 minutes after the formation of pneumoperitoneum, the PCV-VG mode group had a lower air peak pressure. However, there was no statistical significance between the two groups in the subgroup analysis 30 min after the formation of pneumoperitoneum, which may be caused by the insufficient sample size.

Pmean is related to the volume at the end of inspiration. The higher the pressure is, the larger the lung volume at the end of inspiration will be. Excessive expansion of alveoli can damage the alveolar membrane and the basement membrane of pulmonary blood vessels, leading to volume-related damage. In this study, the average airway pressure of laparoscopic patients was also lower under PCV-VG mode.

Lung compliance means the changes in lung volume caused by the change of unit pressure, and it expresses the effect of chest pressure on lung volume, which is equivalent to the elasticity of lung tissue. Cdyn refers to lung compliance measured during the respiratory cycle when airflow is not blocked, and which is negatively correlated with Ppeak. Studies [12,37] indicated that Cdyn decreased by $25 \%-40 \%$ in patients with mechanical ventilation after pneumoperitoneum. In addition, lateral decubitus reduces lung compliance, increase airway resistance, limits diastolic contraction of the lung, and leading to the imbalance of ventilation and blood supply, etc., all of which could result in partial alveolar collapse and failure to participate in ventilation, limiting the removal of $\mathrm{CO} 2$ and posing a threat to the perioperative safety of patients. Retroperitoneal laparoscopic surgery, as an extension of the abdominal cavity mirror operation, is widely used in urology presently. The so-called posterior peritoneal cavity is not a truly anatomical cavity. In the retroperitoneal laparoscopic surgery, a certain pressure of CO2 gas is injected into the posterior peritoneal cavity based on the patient's lateral folding position, and a potential cavity is opened for surgical operation [38]. Three special points of retroperitoneal laparoscopic surgery: lateral position, folding position, and $\mathrm{CO} 2$ pneumoperitoneum. The combination of the three points is more likely to cause the mismatch between ventilator parameters and the patient's physiological parameters, leading to ventilator-related lung injury and hypercapnia, affecting the human respiratory and circulatory systems. In severe cases, it will increase blood pressure, increase heart rate and pulmonary vascular resistance, leading to decreased pulmonary compliance and intrapulmonary shunt [24,27]. Therefore, "individualized ventilation" was adopted according to patients' vital signs and respiratory mechanics in post- 
laparoscopic surgery, aiming to reduce the occurrence degree of ventilator-related lung injury. This study found that in the retroperitoneal laparoscopic surgery, the Ppeak of the PCV-VG group was lower than that of the VCV group.

In addition, in our study, it was found that after the formation of pneumoperitoneum, PCV-VG mode could not significantly reduce PetCO2 and $\mathrm{PaCO} 2$ compared with VCV mode, which was different from our previous hypothesis. In previous studies [12], studies indicated that PetCO2 and PaCO2 in the PCV-VG group decreased significantly during and after pneumoperitoneum. This may be due to inadequate sample size. At the same time, there was no statistically significant difference between the two ventilation modes of $\mathrm{PH}$ and $\mathrm{PaO} 2$, which was consistent with the studies of El-Ramely and Rachel $[32,39]$. The above results indicated that PCV-VG mode had no obvious advantages in improving oxygenation and ventilation compared with VCV mode.

In this meta-analysis, we included patients who were non-morbidly obese patients without preoperative lung injury. According to previous studies [12], experiments based on the healthy population can more accurately reflect the influence of laparoscopic pneumoperitoneum on patients. We did not include patients with restrictive and obstructive pulmonary disease, so the direct impact of ventilation patterns could be better assessed. However, there was also has some limitations in our article. Firstly, due to the limited data of the trials, we did not analyze the respiratory mechanics, hemodynamic blood gas analysis and postoperative complications of patients after pneumoperitoneum; Secondly, we only included adult patients with double-lung ventilation, and the included patients did not include pediatric patients and patients with single-lung ventilation; Finally, we included patients who were non-morbidly obese and had no preoperative lung injury. The results of these patients may be different from the results of this metaanalysis. Therefore, more high-quality, multi-center randomized controlled trials are expected to address these issues.

\section{Conclusions}

PCV-VG mode are superior to VCV mode in providing adequate oxygenation at lower airway peak pressure and greater dynamic compliance in patients under laparoscopic surgery.

\section{Declarations}

\section{Acknowledgements}

This study was supported by Jiangsu Province Key Laboratory of Anesthesiology, Xuzhou Medical University, Xuzhou, China.

\section{Funding}

This study was supported by a grant from the National Natural Science Foundation of China (NSFC81371242, NSFC-81671084), Qing Lan Project of Jiangsu province, Nature Science Foundation of 
Jiangsu province (BK20161175), and “Six One” Project of Jiangsu province (LGY2016039).

\section{Availability of data and material}

All relevant data and materials are presented in the manuscript.

\section{Author's contributions}

$X X L, S L$ conceived the idea for this systematic review. XLL, XXL and ZFJ developed the methodology for the systematic review, and $X X L$ and $X R N$ supervised the methodological process. The manuscript was drafted by XXL and SL. All authors critically reviewed and approved the final manuscript.

\section{Conflict of interests}

The authors declare that they have no competing interests.

\section{Ethics approval and consent to participate}

Ethics approval and consent to participate is not required because this is a protocol for a systematic review and meta-analysis in which no primary human data will be collected.

\section{Reference}

[1] Pache B, Hübner M, Jurt J, Demartines N, Grass F. Minimally invasive surgery and enhanced recovery after surgery: The ideal combination? J Surg Oncol. 2017;116(5):613-6.

[2] Joly LM, Benhamou D. Laparoscopic surgery. Lancet. 2001;357(9261):1045.

[3] Cunningham AJ, Brull SJ. Laparoscopic cholecystectomy: Anesthetic implications. Anesth Analg 1993; 76:1120-33.

[4] Oğurlu M, Küçük M, Bilgin F, Sizlan A, Yanarateş O, Eksert S, Karaşahin E, Coşar A. Pressure-controlled vs volume-controlled ventilation during laparoscopic gynecologic surgery. J Minim Invasive Gynecol. 2010;17(3):295-300.

[5] Grieco DL, Anzellotti GM, Russo A, Bongiovanni F, Costantini B, D'Indinosante M, Varone F, Cavallaro F. Airway Closure during Surgical Pneumoperitoneum in Obese Patients. Anesthesiology. 2019;14.

[6] Haines KL, Agarwal S. Postoperative Pulmonary Complications-A Multifactorial Outcome. JAMA Surg. 2017;152(2):166-7.

[7] Costa Leme A, Hajjar LA, Volpe MS, Fukushima JT, De Santis Santiago RR, Osawa EA, Pinheiro de Almeida J. Effect of Intensive vs Moderate Alveolar Recruitment Strategies Added to Lung-Protective Ventilation on Postoperative Pulmonary Complications: A Randomized Clinical Trial. JAMA. 2017;317(14):1422-32. 
[8] Lee JH, Bae JI, Jang YE, Kim EH, Kim HS, Kim JT. Lung protective ventilation during pulmonary resection in children: a prospective, single-centre, randomised controlled trial. Br J Anaesth. 2019;7.

[9] Assad OM, El Sayed AA, Khalil MA. Comparison of volume-controlled ventilation and pressurecontrolled ventilation volume guaranteed during laparoscopic surgery in Trendelenburg position. $J$ Clin Anesth. 2016; 34:55-61.

[10] Schädler D, Weiler N. Lung protective ventilation. Ventilatory modes and ventilator parameters. Anasthesiol Intensivmed Notfallmed Schmerzther. 2008;43(6):448-53.

[11] Maeda Y, Fujino Y, Uchiyama A, Matsuura N, Mashimo T, Nishimura M. Effects of peak inspiratory flow on development of ventilator-induced lung injury in rabbits. Anesthesiology. 2004; 101:722-8.

[12] Kothari A, Baskaran D. Pressure-controlled Volume Guaranteed Mode Improves Respiratory Dynamics during Laparoscopic Cholecystectomy: A Comparison with Conventional Modes. Anesth Essays Res. 2018;12(1):206-12.

[13] Keszler M, Abubakar K. Volume guarantee: Stability of tidal volume and incidence of hypocarbia. Pediatr Pulmonol. 2004;38:240-5.

[14] Keszler M. Volume-targeted ventilation. Early Hum Dev. 2006;82:811-8.

[15] Song SY, Jung JY, Cho MS, Kim JH, Ryu TH, Kim BI. Volume-controlled versus pressure-controlled ventilation-volume guaranteed mode during one-lung ventilation. Korean J Anesthesiol. 2014;67(4):25863.

[16] Kim MS, Soh S, Kim SY, Song MS, Park JH. Comparisons of Pressure-controlled Ventilation with Volume Guarantee and Volume-controlled 1:1 Equal Ratio Ventilation on Oxygenation and Respiratory Mechanics during Robot-assisted Laparoscopic Radical Prostatectomy: A Randomized-controlled Trial. Int J Med Sci. 2018;15(13):1522-9.

[17] JP Higgins, SG Thompson, JJ Deeks, DG Altman. Measuring inconsistency in meta-analyses. BMJ. 2003; 327:557-560.

[18] R DerSimonian, R Kacker, Random-effects model for meta-analysis of clinical trials: an update. Contemp Clin Trials. 2007; 28:105-14.

[19] Sasagawa I, Suzuki H, Izumi T, Tateno T, Shoji N, Kubota Y, Nakada T. Pulmonary function after posterior retroperitoneoscopic surgery. Int Urol Nephrol. 1998;30(6):695-8.

[20] Chung HJ, Chiu AW, Chen KK, Huang WJ, Hsu YS, Chang LS. Alterations in pulmonary function after retroperitoneoscopic surgery. Br J Urol. 1996;78(6):821-5. 
[21] Khoder WY, Waidelich R, Ghamdi AMA, Schulz T, Becker A, Stief CG. A prospective randomised comparison between the transperitoneal and retroperitoneoscopic approaches for robotic-assisted pyeloplasty in a single surgeon, single centre study. J Robot Surg. 2018;12(1):131-7.

[22] Bai J, Ma L, Meng LH, Zhang PB, Liu HT. Effect of pressure-controlled ventilation-volume guaranteed mode on respiratory mechanics in gynecologic laparoscopic surgery. Int J Anesth Resus. 2018; 39(10): 934-7.

[23] Dong JM, Xu ZF. Application of pressure-controlled ventilation-volume guaranteed during laparoscopic cholecystectomy. World Chin J Digest. 2017; 25(6): 560-4.

[24] Feng XX, Feng KP, Luan XZ, Zhang M, Wu L. Study on safety of pressure control-volume guarantee ventilation administrated in elderly patients undergoing retroperitoneoscopy. J Logist Uni CAPF. 2014; 23(5): 384-7.

[25] Gao YJ, Ding SL, Liu RB, Yan WJ, Li T. The clinical study of lung protective ventilation strategy in laparoscopic surgery under general anesthesia. Yiayao Qianyan. 2018;8(16): 16-7.

[26] Ding SL, Gao YJ, Yan WJ, Huang JW, Liu RB, He M, Wang D, Ding PY, Deng F, Feng XX. Effect of Different Ventilation Modes on Lung Protection and Pulmonary Function Optimization in Elderly Patients under Laparoscopic Surgery. J Med Theor \& Prac. 2018;31(4): 472-4.

[27] La J, Tian SY, Wang X, Su XS, Yuan X, Zhang R, Liu SF, Li C. Effect of different ventilation modes on lung injury in patients performed with retroperitoneal laparoscopic surgeries. Chin Mod Med. 2018;25(23): 60-3.

[28] Li K, Luo AL, Li BX, Luo ZB, Zhou X, Liu TG, Song XY, Tao J. Clinical Observation of PCV-VG on Respiratory Mechanics Used for Retroperitoneal Laparoscopic Surgery. Mil Med J S Chin. 2017;31(5):3058.

[29] Wang R, Wang W, Meng B, Fang XM. Effects of two different mechanical ventilation modes on lung protection in elderly rectal cancer patients undergoing laparoscopic radical surgery. Shanghai Med J. 2018;41(5):280-3.

[30] Zhou HZ, Hu XK, Shen HC, Wang QS, Chen JP. Comparison of effects of different ventilation modes in laparoscopic radical resection of rectal cancer in elderly patients. Chin J Rur Med Phar. 2015; 22(19): 11-3.

[31] Aldenkortt M, Lysakowski C, Elia N, Brochard L, Tramèr MR. Ventilation strategies in obese patients undergoing surgery: a quantitative systematic review and meta-analysis. $\mathrm{Br} \mathrm{J}$ Anaesth. 2012;109(4):493502.

[32] El-Ramely MA, Mahmoud AAA, Abdelhaq MM. The dual mode of ventilation 'pressure-controlled ventilation-volume guaranteed' does not provide any more benefit in obese anesthetized patients. Egypt $J$ 
Cardiothorac Anesth. 2015; 9:39-45.

[33] Maeda Y, Fujino Y, Uchiyama A, Matsuura N, Mashimo T, Nishimura M. Effects of peak inspiratory flow on development of ventilator-induced lung injury in rabbits. Anesthesiology. 2004;101(3):722-8.

[34] Eisner MD, Thompson BT, Schoenfeld D, Anzueto A, Matthay MA;Acute Respiratory Distress Syndrome Network. Airway pressures and early barotrauma in patients with acute lung injury and acute respiratory distress syndrome. Am J Respir Crit Care Med. 2002;165:978-82.

[35] Boules NS, Ghobrial HZ. Efficiency of a newly introduced mode pressure-controlled volume guaranteed mode in thoracic surgery with one lung ventilation. Egypt $J$ Anaesth. 2011; 27:113-9.

[36] Dion JM, McKee C, Tobias JD, Sohner P, Herz D, Teich S, et al. Venti- lation during laparoscopicassisted bariatric surgery: volume-controlled, pressure-controlled or volume-guaranteed pressureregulated modes. Int J Clin Exp Med. 2014;7(8):2242-7.

[37] Gutt CN, Oniu T, Mehrabi A, Schemmer P, Kashfi A, Kraus T, et al. Circulatory and respiratory complications of carbon dioxide insufflation. Dig Surg. 2004; 21:95-105.

[38] Lombardo R, Martos R, Ribal MJ, Alcaraz A, Tubaro A, De Nunzio C. Retroperitoneoscopy in urology: a systematic review. Minerva Urol Nefrol. 2019;71(1):9-16.

[39] Rachel J, Jason G, Ari M. Ventilation Modes for Obese Patients Under Mechanical Ventilation. Mechanical Ventilation in the Critically III Obese Patient. 2017;22: 163-77.

\section{Table 1}

Due to technical limitations, Table 1 is only available as a download in the supplemental files section.

\section{Figures}



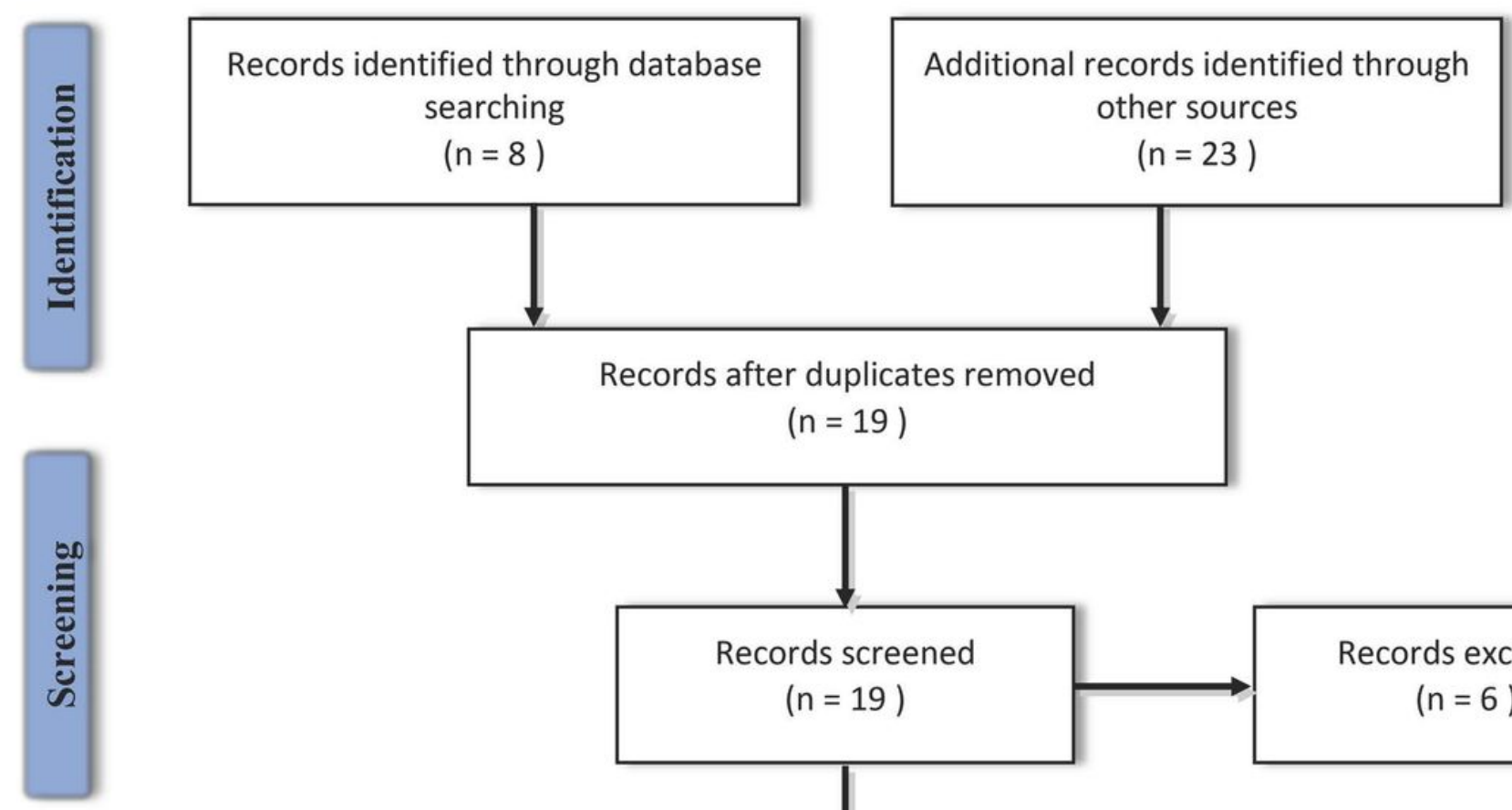

Records after duplicates removed

$$
(n=19)
$$
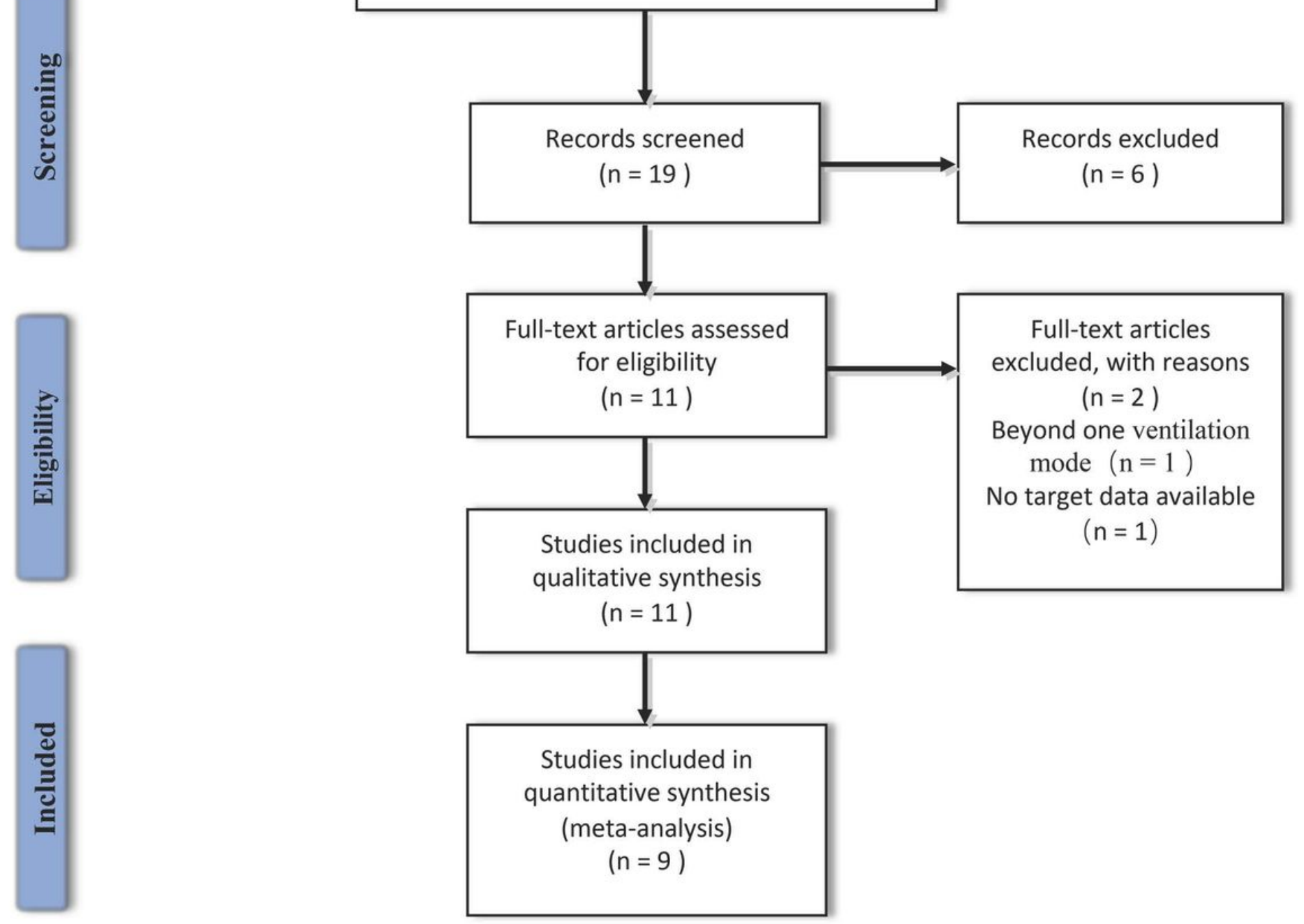

\section{Figure 1}

Flow-chart of the literature search strategy. 


\section{Random sequence generation (selection bias)}

\section{Allocation concealment (selection bias)}

Blinding of participants and personnel (performance bias)

Blinding of outcome assessment (detection bias)

Incomplete outcome data (attrition bias)

Selective reporting (reporting bias)

Other bias

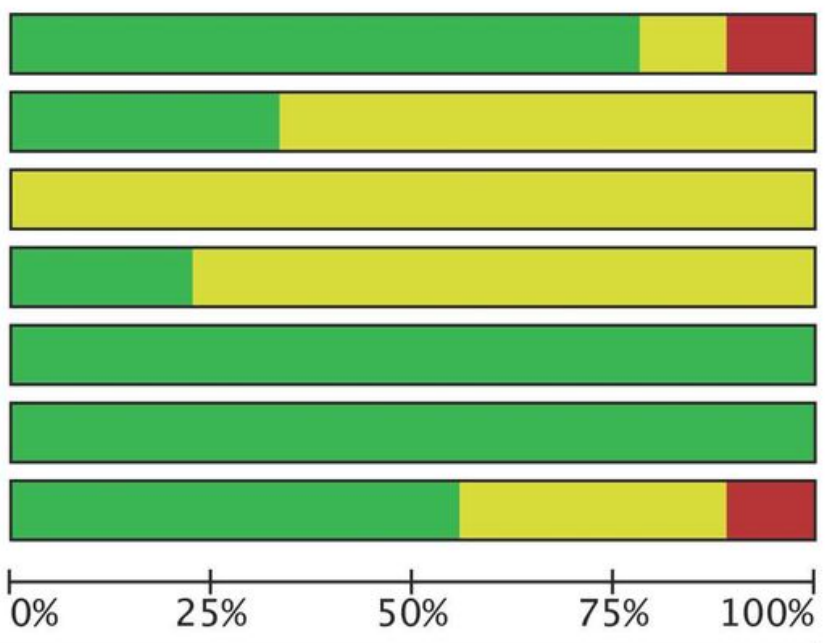

\section{Figure 2}

Risk-of-bias graph of all the included randomized controlled trials.

\section{Ppeak at 30mins}

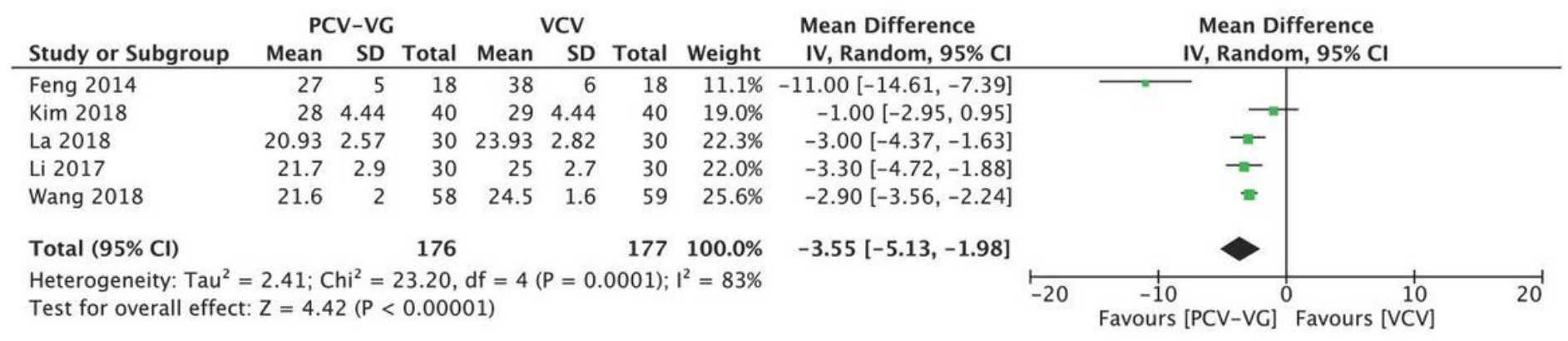

\section{Ppeak at 60mins}

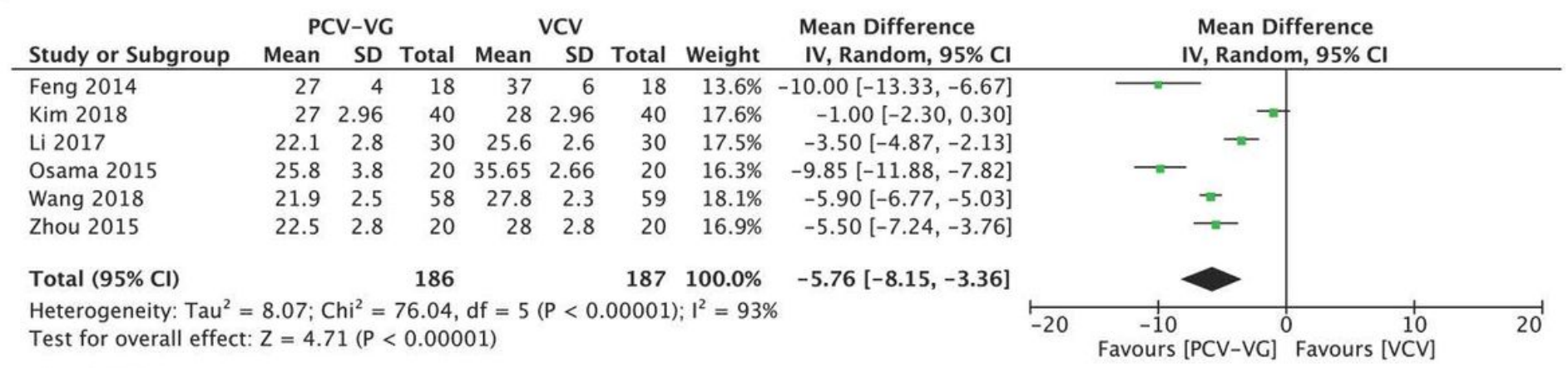

\section{Ppeak at 90mins}

\begin{tabular}{|c|c|c|c|c|c|c|c|c|c|c|c|c|}
\hline \multirow[b]{2}{*}{ Study or Subgroup } & \multicolumn{3}{|c|}{ PCV-VG } & \multicolumn{3}{|c|}{ VCV } & \multicolumn{2}{|r|}{ Mean Difference } & \multirow{2}{*}{\multicolumn{4}{|c|}{$\begin{array}{c}\text { Mean Difference } \\
\text { IV, Random, } 95 \% \mathrm{CI}\end{array}$}} \\
\hline & Mean & SD & Total & Mean & SD & Total & Weight & IV, Random, 95\% Cl & & & & \\
\hline La 2018 & 21.97 & 2.86 & 30 & 26.03 & 2.91 & 30 & $25.3 \%$ & $-4.06[-5.52,-2.60]$ & & $\square-$ & & \\
\hline Li 2017 & 22.5 & 2.8 & 30 & 26.5 & 2.7 & 30 & $27.2 \%$ & $-4.00[-5.39,-2.61]$ & & - & & \\
\hline Wang 2018 & 23.6 & 2.3 & 58 & 28.8 & 2.7 & 59 & $47.5 \%$ & $-5.20[-6.11,-4.29]$ & & $-1-$ & & \\
\hline Total $(95 \% \mathrm{Cl})$ & & & 118 & & & 119 & $100.0 \%$ & $-4.59[-5.43,-3.74]$ & & & & \\
\hline $\begin{array}{l}\text { Heterogeneity: } \mathrm{Tau}^{2} \\
\text { Test for overall effec }\end{array}$ & $\begin{array}{l}0.17 ; C \\
Z=10\end{array}$ & $\begin{array}{l}h^{2}= \\
68(P\end{array}$ & $\begin{array}{l}2.87, d \\
<0.000\end{array}$ & $\begin{array}{l}f=2(P \\
01)\end{array}$ & $=0.2$ & $; 1^{2}=$ & $30 \%$ & & -10 & $\begin{array}{l}-5 \\
\text { avours [PCV- }\end{array}$ & $\begin{array}{cc}0 & 5 \\
\text { Favours [VCV] }\end{array}$ & 10 \\
\hline
\end{tabular}


Meta-analysis of the Ppeak in patients under PCV-VG and VCV mode during laparoscopic surgery. Ppeak at $30 \mathrm{mins}$

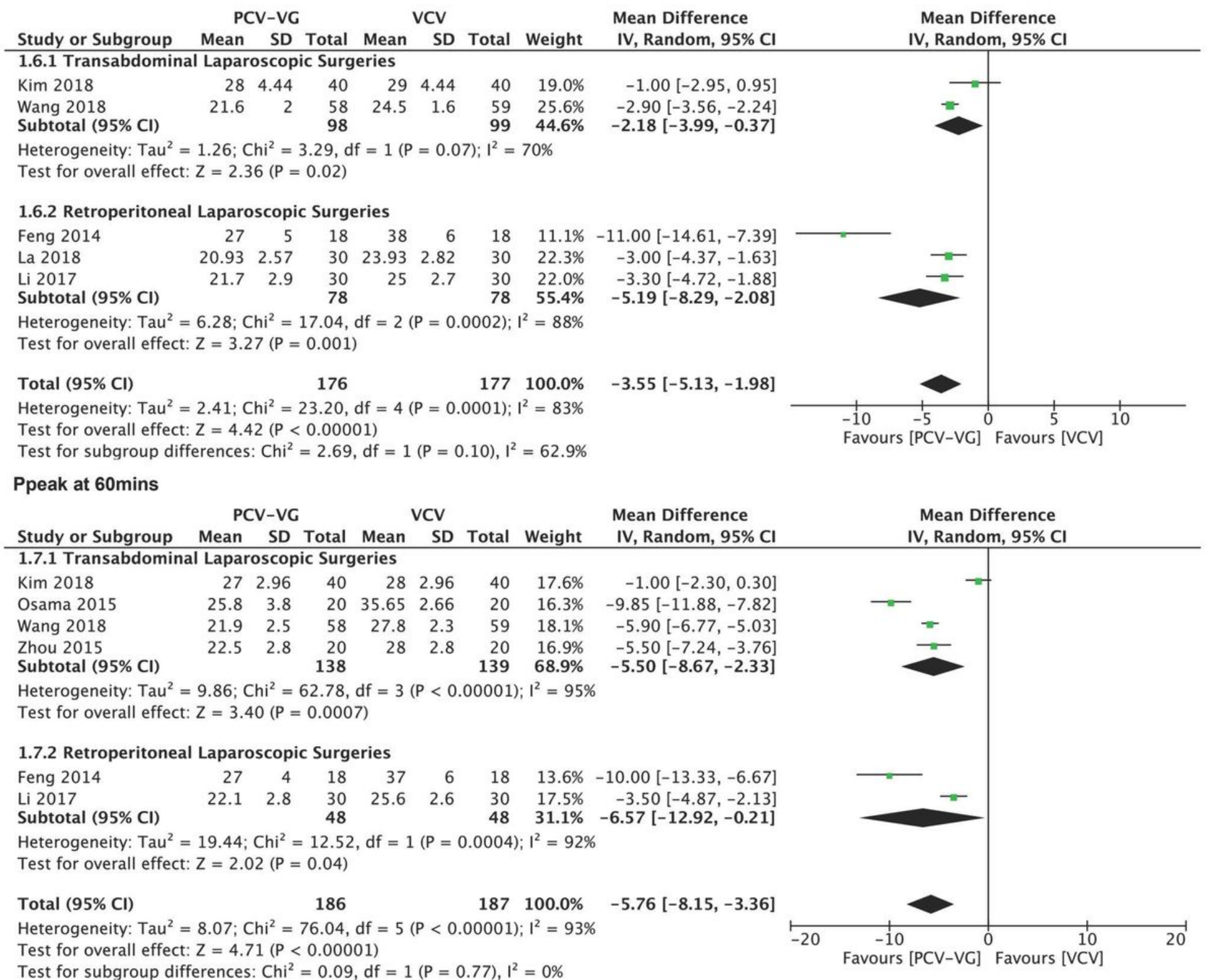

\section{Figure 4}

Subgroup analysis of Ppeak in patients under PCV-VG and VCV mode during laparoscopic surgery. 
Pmean at 30 mins

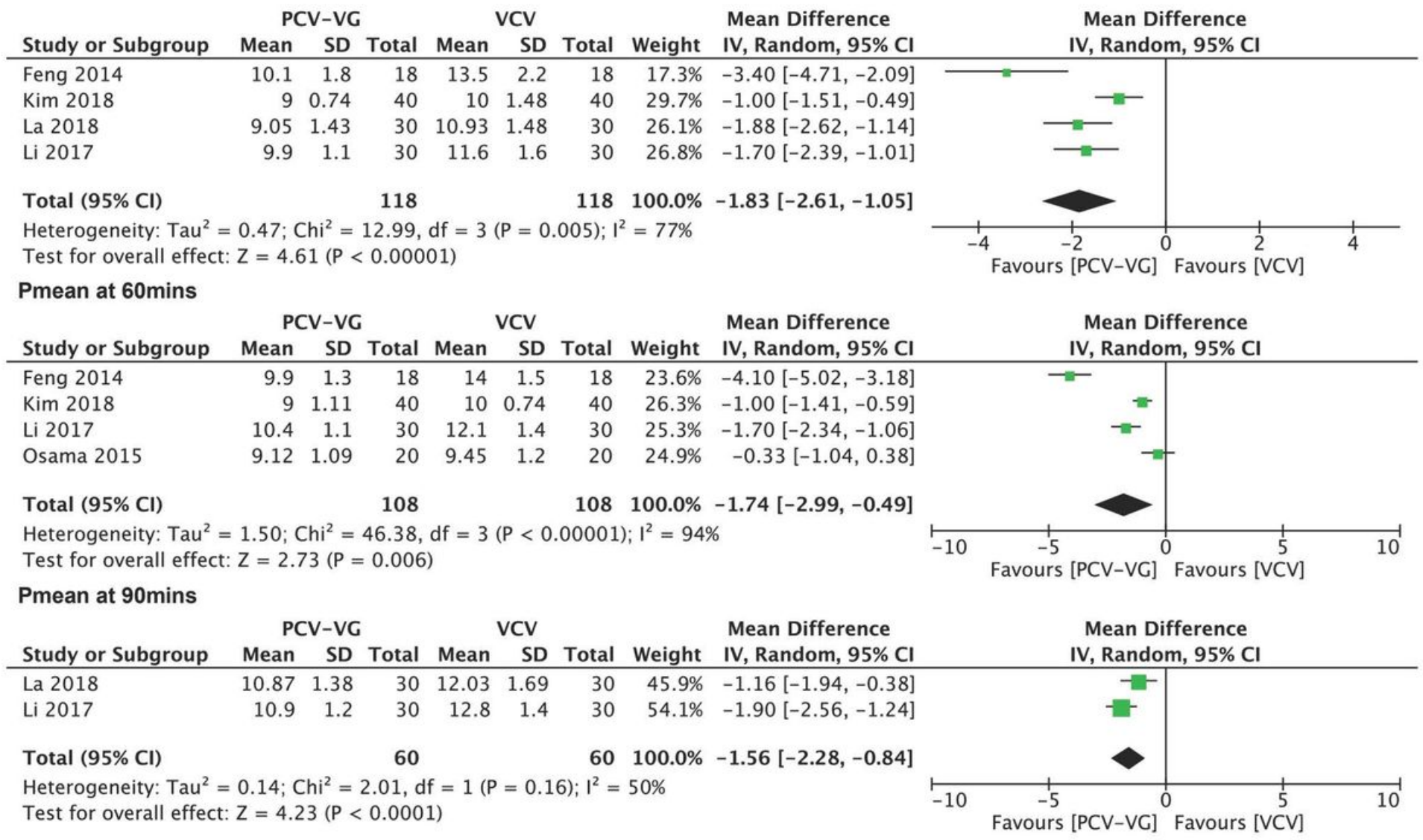

\section{Figure 5}

Meta-analysis of Pmean in patients under PCV-VG and VCV mode during laparoscopic surgery. Cdyn at 30 mins

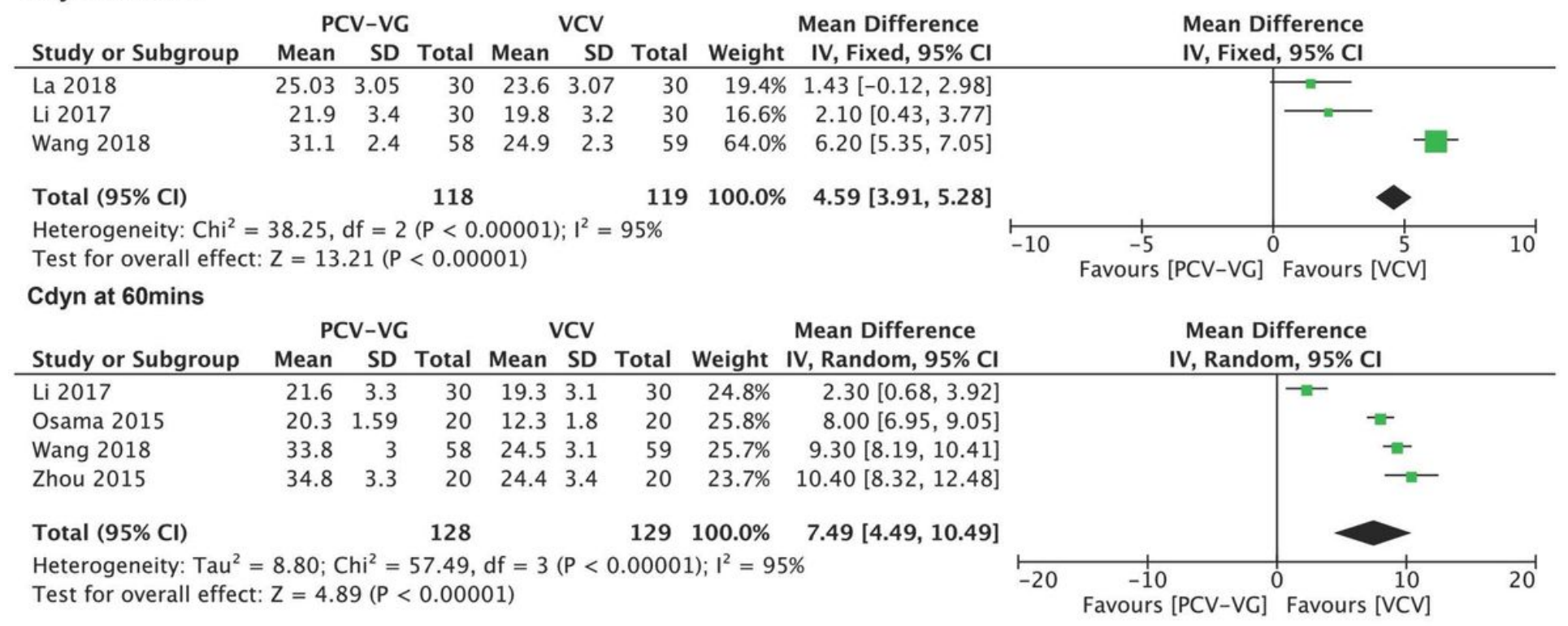

\section{Figure 6}

Meta-analysis of Cdyn in patients under PCV-VG and VCV mode during laparoscopic surgery. 
PetCO2 at 30 mins

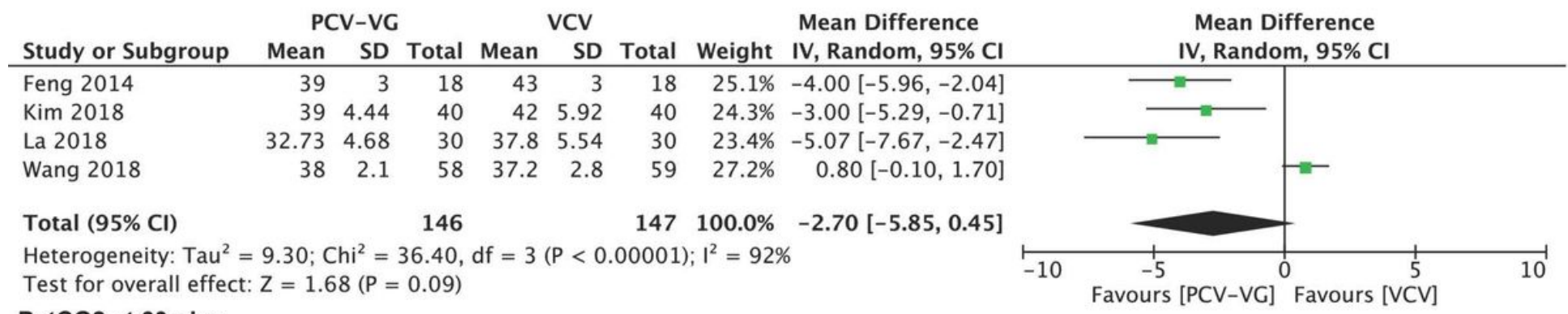

\section{PetCO2 at $60 \mathrm{mins}$}

\begin{tabular}{|c|c|c|c|c|c|c|c|c|}
\hline \multirow[b]{2}{*}{ Study or Subgroup } & \multicolumn{3}{|c|}{ PCV-VG } & \multicolumn{3}{|c|}{ VCV } & \multicolumn{2}{|r|}{ Mean Difference } \\
\hline & Mean & SD & Total & Mean & SD & Total & Weight & IV, Random, 95\% CI \\
\hline Feng 2014 & 42 & 4 & 18 & 46 & 2 & 18 & $18.2 \%$ & $-4.00[-6.07,-1.93]$ \\
\hline Kim 2018 & 41 & 4.44 & 40 & 41 & 4.44 & 40 & $19.2 \%$ & $0.00[-1.95,1.95]$ \\
\hline Osama 2015 & 40.3 & 3.8 & 20 & 40.65 & 3.08 & 20 & $17.6 \%$ & $-0.35[-2.49,1.79]$ \\
\hline Wang 2018 & 38.1 & 3.5 & 58 & 38.6 & 3 & 59 & $26.3 \%$ & $-0.50[-1.68,0.68]$ \\
\hline Zhou 2015 & 33.1 & 3.5 & 20 & 33.6 & 3 & 20 & $18.6 \%$ & $-0.50[-2.52,1.52]$ \\
\hline Total $(95 \% \mathrm{Cl})$ & & & 156 & & & 157 & $100.0 \%$ & $-1.02[-2.32,0.29]$ \\
\hline
\end{tabular}

Heterogeneity: $\mathrm{Tau}^{2}=1.33 ; \mathrm{Chi}^{2}=10.31, \mathrm{df}=4(\mathrm{P}=0.04) ; \mathrm{I}^{2}=61 \%$

Test for overall effect: $Z=1.52(P=0.13)$

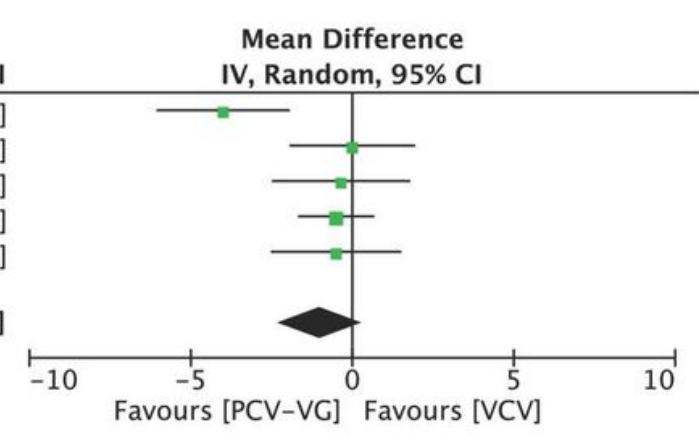

PetCO2 at 90mins

\begin{tabular}{|c|c|c|c|c|c|c|c|c|}
\hline \multirow[b]{2}{*}{ Study or Subgroup } & \multicolumn{3}{|c|}{ PCV-VG } & \multicolumn{3}{|c|}{ VCV } & \multicolumn{2}{|r|}{ Mean Difference } \\
\hline & Mean & SD & Total & Mean & SD & Total & Weight & IV, Random, 95\% CI \\
\hline La 2018 & 42.37 & 3.64 & 30 & 41 & 5.95 & 30 & $29.9 \%$ & $1.37[-1.13,3.87]$ \\
\hline Wang 2018 & 38.7 & 2.7 & 58 & 39.2 & 2.3 & 59 & $70.1 \%$ & $-0.50[-1.41,0.41]$ \\
\hline Total $(95 \% \mathrm{Cl})$ & & & 88 & & & 89 & $100.0 \%$ & $0.06[-1.62,1.74]$ \\
\hline
\end{tabular}

Heterogeneity: $\mathrm{Tau}^{2}=0.83 ; \mathrm{Chi}^{2}=1.90, \mathrm{df}=1(\mathrm{P}=0.17) ; \mathrm{I}^{2}=47 \%$

Test for overall effect: $Z=0.07(P=0.95)$

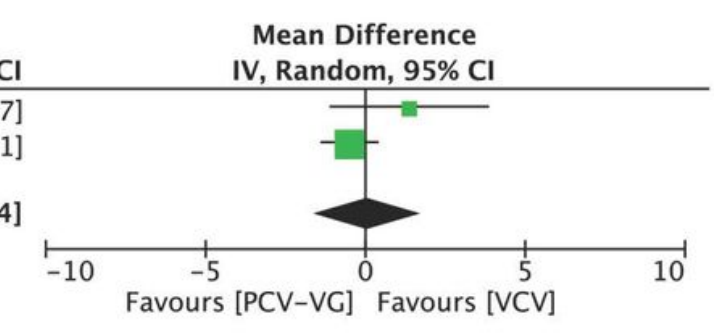

\section{Figure 7}

Meta-analysis of PetCO2 in patients under PCV-VG and VCV mode during laparoscopic surgery.

$\mathrm{HR}$ at $60 \mathrm{mins}$

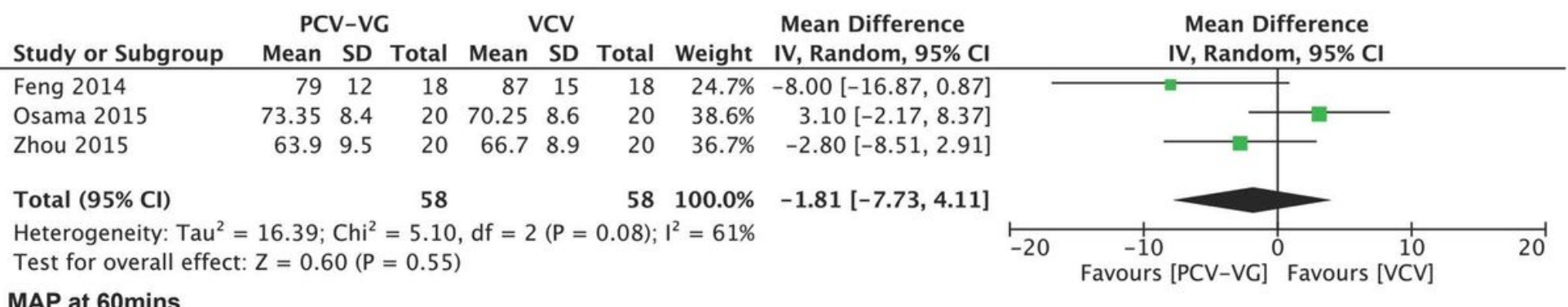

\section{MAP at $60 \mathrm{mins}$}

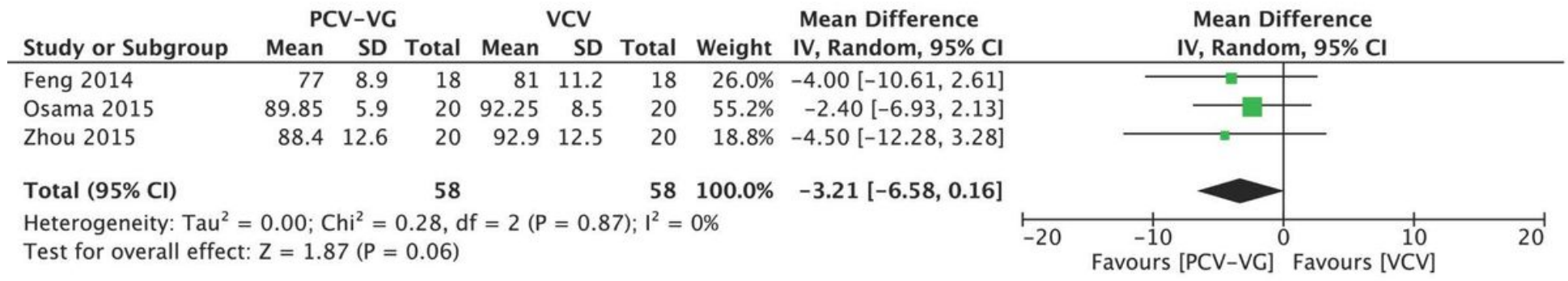

\section{Figure 8}

Meta-analysis of HR and MAP in patients under PCV-VG and VCV mode during laparoscopic surgery. 
$\mathrm{PH}$ at 30mins

\begin{tabular}{ccccc} 
& \multicolumn{2}{c}{ PCV-VG } & \multicolumn{2}{c}{ Mean Difference } \\
Study or Subgroup Mean SD Total Mean SD Total Weight IV, Random, $95 \% \mathrm{CI}$
\end{tabular}

$\begin{array}{lllllllll}\text { Feng 2014 } & 7.38 & 0.09 & 18 & 7.34 & 0.08 & 18 & 13.1 \% & 0.04[-0.02,0.10] \\ \text { Gao1 2018 } & 7.37 & 0.08 & 75 & 7.36 & 0.08 & 75 & 61.9 \% & 0.01[-0.02,0.04] \\ \text { Kim 2018 } & 7.35 & 0.05 & 40 & 7.35 & 0.12 & 40 & 25.0 \% & 0.00[-0.04,0.04]\end{array}$

Kim 2018

133

$133100.0 \%$

Total $(95 \% \mathrm{Cl})$

$33, \mathrm{df}=2(\mathrm{P}=0.51) ; \mathrm{I}^{2}=0 \%$

Heterogeneity: $\mathrm{Tau}^{2}=0.00 ; \mathrm{Chi}^{2}=1.33$, $\mathrm{d}$
Test for overall effect: $\mathrm{Z}=1.11(\mathrm{P}=0.27)$

$\mathrm{PH}$ at $60 \mathrm{mins}$

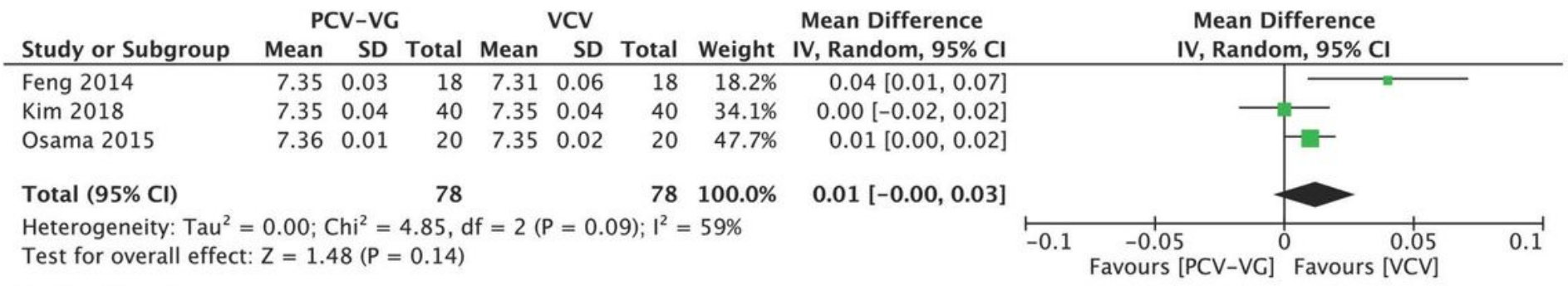

\section{$\mathrm{PaO} 2$ at $60 \mathrm{mins}$}

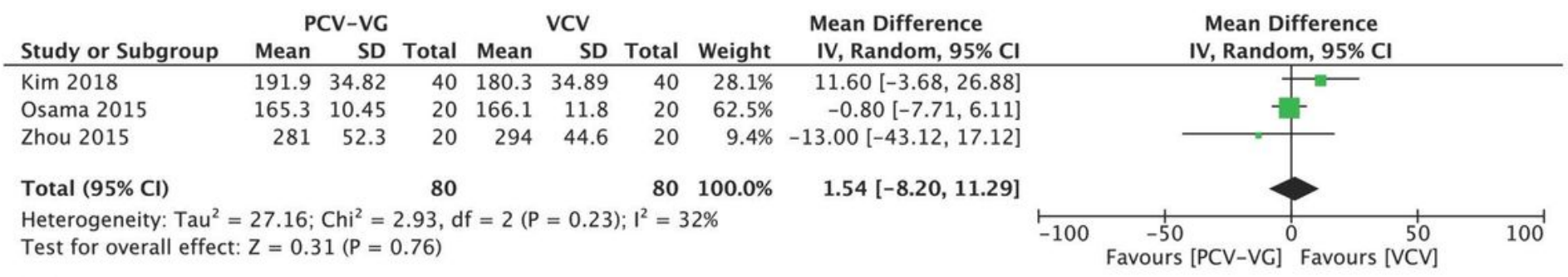

\section{$\mathrm{PaCO} 2$ at 30mins}

\begin{tabular}{|c|c|c|c|c|c|c|c|c|c|c|c|c|}
\hline \multirow[b]{2}{*}{ Study or Subgroup } & \multicolumn{3}{|c|}{ PCV-VG } & \multicolumn{3}{|c|}{ VCV } & \multicolumn{3}{|c|}{ Mean Difference } & \multirow{2}{*}{\multicolumn{3}{|c|}{$\begin{array}{c}\text { Mean Difference } \\
\text { IV, Random, } 95 \% \mathrm{Cl}\end{array}$}} \\
\hline & Mean & SD & Total & Mean & SD & Total & Weight & IV, Random, $95 \% \mathrm{Cl}$ & & & & \\
\hline Feng 2014 & 43 & 2 & 18 & 49 & 4 & 18 & $24.2 \%$ & $-6.00[-8.07,-3.93]$ & & $\longrightarrow$ & & \\
\hline Gao1 2018 & 37 & 2 & 75 & 36 & 2 & 75 & $28.8 \%$ & $1.00[0.36,1.64]$ & & & $\rightarrow$ & \\
\hline Kim 2018 & 41.8 & 8.07 & 40 & 44.6 & 7.26 & 40 & $18.7 \%$ & $-2.80[-6.16,0.56]$ & & & $T$ & \\
\hline Wang 2018 & 43.5 & 1.9 & 58 & 42.8 & 3 & 59 & $28.3 \%$ & $0.70[-0.21,1.61]$ & & & $f=-$ & \\
\hline Total $(95 \% \mathrm{CI})$ & & & 191 & & & 192 & $100.0 \%$ & $-1.49[-3.90,0.92]$ & & & & \\
\hline $\begin{array}{l}\text { Heterogeneity: } \mathrm{Tau}^{2} \\
\text { Test for overall effect }\end{array}$ & $\begin{array}{l}5.12 \\
Z=1 .\end{array}$ & $\begin{array}{l}\mathrm{Ch}^{2}= \\
1(\mathrm{P}=\end{array}$ & $\begin{array}{r}44.13 \\
=0.23)\end{array}$ & $\mathrm{df}=3$ & $<0$ & .00001 & $; 1^{2}=93 \%$ & & $\stackrel{-10}{-10}$ & $\begin{array}{c}-5 \\
\text { Favours }\end{array}$ & $\begin{array}{cc}0 & 5 \\
\text { Favours [VCV] }\end{array}$ & 10 \\
\hline
\end{tabular}

\section{$\mathrm{PaCO} 2$ at $60 \mathrm{mins}$}

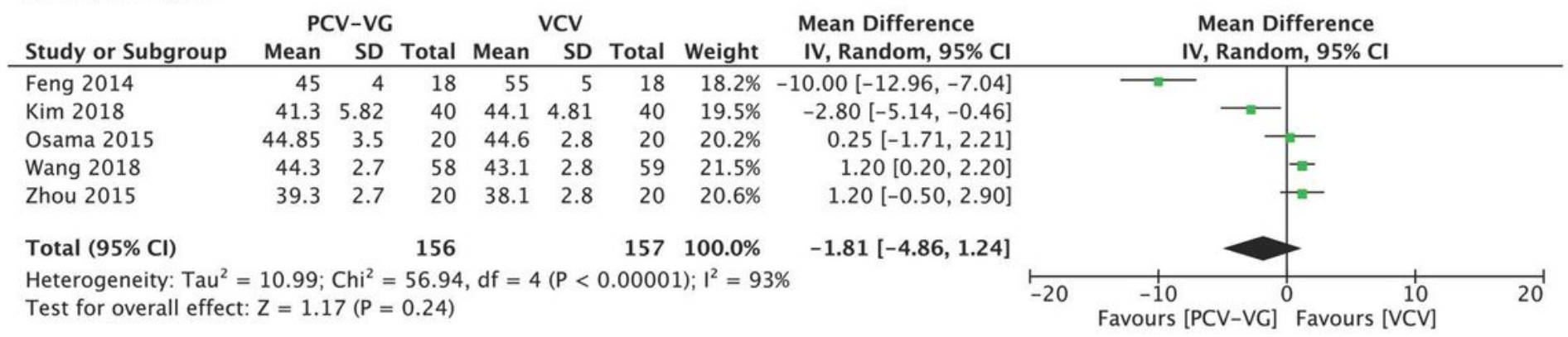

\section{Figure 9}

Meta-analysis of the $\mathrm{PH}, \mathrm{PaO} 2$ and $\mathrm{PaCO} 2$ in patients under PCV-VG and VCV mode during laparoscopic surgery.

\section{Supplementary Files}

This is a list of supplementary files associated with this preprint. Click to download. 
- supplement1.docx

- supplement2.pdf 